\title{
Comportamento ingestivo e digestibilidade de nutrientes em vacas submetidas a diferentes níveis de concentrado
}

\author{
[Ingestive behavior and nutrient digestibility in cows fed different levels of concentrate] \\ S.R. Goularte ${ }^{1}$, L.C.V. Ítavo², C.C.B.F. Ítavo ${ }^{3}$, A.M. Dias², M.G. Morais ${ }^{3}$, \\ G.T. Santos ${ }^{4}$, L.C.S. Oliveira ${ }^{3}$ \\ ${ }^{1}$ Universidade Católica Dom Bosco - Campo Grande, MS - Bolsista FUNDECT \\ ${ }^{2}$ Universidade Católica Dom Bosco - Campo Grande, MS - Pesquisador CNPq \\ ${ }^{3}$ Universidade Federal de Mato Grosso do Sul - Campo Grande, MS \\ ${ }^{4}$ Universidade Estadual de Maringá - Maringá, PR
}

\begin{abstract}
RESUMO
Avaliou-se a influência do teor de concentrado na dieta sobre o comportamento ingestivo, o consumo e a digestibilidade aparente de nutrientes em bovinos. Foram utilizadas quatro vacas mestiças, com média de peso de 442,15kg, distribuídas em quadrado latino 4x4, durante quatro períodos de 14 dias, sendo 11 de adaptação e três para coleta de amostras, elaboradas por animal e por período. O comportamento foi avaliado pela observação dos animais a cada 15 minutos por 24 horas, determinando-se tempo de alimentação, ruminação, ócio e ingestão de água. Utilizou-se silagem de milho como volumoso e concentrado à base de milho, sorgo, farelo de soja, casca de soja, suplemento mineral, ureia e gordura protegida, em dietas com $13 \%$ de proteína bruta. As proporções de concentrado foram de 30, 40, 50 e $60 \%$, na matéria seca. As atividades de consumo e ruminação diminuíram linearmente em função do teor de concentrado, e o tempo de ócio aumentou. Houve efeito linear da porcentagem de concentrado para eficiência do consumo e de ruminação, bem como consumo dos nutrientes da dieta, com exceção da fibra em detergente neutro. O aumento do teor de concentrado diminuiu o tempo de apreensão e ingestão e de ruminação, e não alterou a digestibilidade dos nutrientes da dieta.
\end{abstract}

Palavras-chave: vaca leiteira, ingestão, ruminação, ócio, volumoso, concentrado

\begin{abstract}
The influence of concentrate levels in rations on ingestion behavior, nutrient intake, and digestibility was determined in cattle. Four $442.15 \mathrm{~kg}$ BW crossbred cows were distributed in a $4 \times 4$ Latin square, into four periods of 14 days, 11 days for adaptation and three days for sample collections per animal and per period. Behavior was determined by observing each animal every 15 minutes for 24 hours, recording feeding, rumination, idling, and water uptake time. The roughage was whole-plant corn silage and the concentrate was composed of corn, sorghum, soybean meal and hulls, minerals, urea, and protected fat, in rations with $13 \%$ crude protein. The concentrate levels were 30, 40, 50, and 60\% in dry matter. Intake and rumination activities decreased linearly with the concentrate level, and consequently, there was increasing idling time. A linear effect was observed for concentrate levels on intake and rumination efficiencies, as well as for intake of the dietary nutrients, but not for neutral detergent fiber intake. Increases in the concentrate level decreased feeding and rumination times, but did not alter nutrient digestibility in the diet.
\end{abstract}

Keywords: dairy cattle, intake, rumination, idling, roughage, concentrate

Recebido em 18 de março de 2010

Aceito em 14 de fevereiro de 2011

E-mail: sandra.goularte@gmail.com 


\section{INTRODUÇÃO}

A etologia, que estuda os hábitos dos animais em seu ambiente de criação ou em ambientes modificados, é importante para a eficiência da exploração zootécnica, pois estuda o emprego de melhores técnicas de manejo e alimentação. Esta expectativa vem sendo confirmada com a ampliação e valorização de estudos do comportamento animal aplicados à produção (Paranhos da Costa et al., 2002).

O comportamento ingestivo dos animais consiste em avaliar a quantidade e o valor nutritivo da dieta, bem como estabelecer a relação entre o comportamento e o consumo voluntário, para a obtenção de dados para a melhora do desempenho animal (Albright, 1993). Animais mantidos em confinamento têm melhor desempenho em relação aos mantidos em pastagem por ficarem mais tempo em ócio (Souza et al., 2007). Animais de alta produção apresentam maior exigência em nutrientes. Desse modo, o estudo do comportamento ingestivo pode contornar os problemas relacionados à diminuição do consumo em épocas críticas da produção, com efeitos sobre práticas de manejo e qualidade e quantidade da dieta oferecida (Damasceno et al., 1999; Paranhos da Costa et al., 2002).

A melhora nutricional pode ocorrer ao se manusear a relação volumoso:concentrado, a qual pode influenciar o consumo do alimento, o desempenho e a viabilidade econômica, assim como ter efeito sobre o comportamento ingestivo (Bürger et al., 2000). Estudos de digestão são importantes para quantificar a absorção dos nutrientes nos diferentes compartimentos do trato gastrintestinal, proporcionando condições mais adequadas de avaliação das dietas e do uso da dieta pelo animal (Resende et al., 2001).

A ingestão de alimentos em bovinos é regulada por três mecanismos. O psicogênico, que envolve a resposta animal a fatores inibidores ou estimuladores relacionados ao alimento e ao ambiente; o fisiológico, no qual o controle é feito pelo balanço nutricional da ração, relacionado à manutenção do equilíbrio energético; e o físico, associado à capacidade de distensão do rúmen e ao teor de fibra em detergente neutro (FDN) da ração (Sniffen et al., 1993).
Para dietas volumosas, a mastigação aumenta a degradação ruminal, por elevar a matéria seca e as frações da fibra potencialmente digerível e reduzir o tempo de latência de degradação da fibra. Para dietas de cereais, os grãos inteiros não são influenciados pela mastigação, tornando a digestão limitada; desse modo, é necessário o processamento do alimento (Beauchemin, 1992).

Uma série de fatores influencia o tempo de apreensão e ingestão, de ruminação e de mastigação, e todo esse processo dura cerca de 4,5 horas. Todas essas etapas podem ser utilizadas para avaliação de características da dieta. Alimentos concentrados e fenos finamente triturados ou peletizados reduzem o tempo de ruminação, enquanto volumosos o aumentam proporcionalmente ao teor de parede celular do volume. $\mathrm{O}$ aumento do consumo tende a diminuir o tempo de ruminação por grama de alimento, fator provavelmente responsável pelo aumento do tamanho das partículas fecais, quando o consumo é elevado (Deswysen et al., 1993; Van Soest, 1994).

A estimativa da digestibilidade é reconhecida como um parâmetro do valor nutritivo do alimento, sendo definida como a fração do alimento ingerido que pode ser absorvida no trato digestivo e não recuperada na excreção fecal (Ítavo et al., 2002a; Cabral et al., 2008). O consumo e a digestibilidade de nutrientes podem estar correlacionados entre si, em função da qualidade da ração. Em rações com digestibilidade dos nutrientes acima de 66\%, há menor resíduo ruminal e rápida renovação de material no rúmen. Forragens de melhor qualidade atingem rapidamente o ponto final de digestão, minimizando a limitação de consumo pelo "enchimento" ruminal (Paterson et al., 1994; Van Soest, 1994).

O suprimento adequado de energia e proteína nos alimentos traz como consequência a melhor utilização dos nutrientes (Freitas et al., 2002). Os concentrados, em relação aos volumosos, apresentam maior concentração energética e podem apresentar baixo incremento calórico, quando estrategicamente usados (Alvim et al., 1999). A adição de gordura à dieta pode elevar o nível energético da dieta, sem aumentar a ingestão de carboidratos não estruturais e sem diminuir a ingestão de fibra. Assim, a substituição de cereais por gordura é um método 
de incrementar a densidade energética sem comprometer o conteúdo em fibra (Palmquist, 1984).

A estimação da digestibilidade é uma das formas de se obter o valor nutritivo de um determinado alimento e sua capacidade em permitir ao animal o uso de nutrientes, em maior ou menor escala (Leão et al., 2005).

O objetivo deste trabalho foi avaliar o efeito de diferentes proporções de concentrado na dieta de vacas leiteiras não lactantes sobre o comportamento ingestivo e a digestibilidade aparente dos nutrientes.

\section{MATERIAL E MÉTODOS}

O experimento foi realizado com quatro vacas leiteiras mestiças, não lactantes, em sistema tie stall, fistuladas no rúmen, com média de peso de 442,15kg. O ensaio foi dividido em quatro períodos experimentais, de 14 dias, compreendendo 11 dias de adaptação à dieta e três dias de coletas - dois dias para coleta de fezes e um dia para avaliação do comportamento -, totalizando 56 dias de ensaio, em quadrado latino 4x4 (quatro tratamentos e quatro períodos).

Os tratamentos consistiram na variação da proporção volumoso:concentrado em: 70:30; 60:40; 50:50 e 40:60, com base na matéria seca. $\mathrm{O}$ volumoso utilizado foi silagem de milho, e o concentrado foi constituído de milho, sorgo, farelo de soja, casca de soja, suplemento mineral, gordura protegida (Megalac-E®) e ureia pecuária como fonte suplementar de nitrogênio para composição de dietas com 13\% de proteína bruta (PB; Tab. 1).

Tabela 1. Composição percentual de ingredientes das dietas e teores de matéria seca, matéria orgânica, proteína bruta, extrato etéreo, fibra em detergente neutro e carboidratos não fibrosos, em função do teor de concentrado

\begin{tabular}{|c|c|c|c|c|}
\hline \multirow{2}{*}{ Ingrediente } & \multicolumn{4}{|c|}{ Concentrado (\%) } \\
\hline & 30 & 40 & 50 & 60 \\
\hline \multicolumn{5}{|c|}{ Composição da dieta (\% MS) } \\
\hline Farelo de soja (27\%) & 8,01 & 10,67 & 13,43 & 16,15 \\
\hline Milho em grão moído (20\%) & 5,93 & 7,91 & 9,95 & 11,96 \\
\hline Casca de soja (20\%) & 5,93 & 7,91 & 9,95 & 11,96 \\
\hline Sorgo em grão moído (20\%) & 5,93 & 7,91 & 9,95 & 11,96 \\
\hline Megalac-E® (9\%) & 2,67 & 3,56 & 4,48 & 5,38 \\
\hline Núcleo mineral (2\%) & 0,60 & 0,79 & 0,99 & 1,20 \\
\hline Ureia (2\%) & 0,60 & 0,79 & 0,99 & 1,20 \\
\hline Total do concentrado & 29,68 & 39,54 & 49,74 & 59,81 \\
\hline Silagem de milho & 68,69 & 59,36 & 49,71 & 40,09 \\
\hline Ureia complementar & 1,64 & 1,10 & 0,55 & 0,00 \\
\hline Total dieta & 100,0 & 100,0 & 100,0 & 100,0 \\
\hline \multicolumn{5}{|c|}{ Composição química } \\
\hline Matéria seca (\%) & 51,37 & 56,02 & 60,67 & 65,32 \\
\hline Matéria orgânica (\%MS) & 95,98 & 96,48 & 96,49 & 98,73 \\
\hline Proteína bruta (\%MS) & 13,50 & 13,28 & 12,96 & 12,91 \\
\hline Extrato etéreo (\%MS) & 3,23 & 3,68 & 4,13 & 4,71 \\
\hline Fibra em detergente neutro (\%MS) & 53,48 & 51,75 & 50,02 & 48,29 \\
\hline Carboidratos não fibrosos (\% MS) & 25,67 & 27,43 & 29,11 & 31,94 \\
\hline
\end{tabular}

O fornecimento da dieta (mistura total) foi realizado uma vez ao dia, de forma a manter as sobras em torno de 5\% do fornecido, em base de matéria seca, com água à vontade. Durante o período de coleta, medidas de consumo de nutrientes foram realizadas diariamente. As dietas fornecidas e as sobras foram coletadas para elaboração de amostras compostas por animal e por período.

Os animais foram submetidos à observação visual a cada 15 minutos, durante 24 horas, para 
avaliação do tempo da apreensão e ingestão, tempo de ruminação, tempo de ócio e tempo de ingestão de água, totalizando 96 horas de observação, divididos em quatro períodos, conforme metodologia de Altman (1974). Durante o período experimental, os animais foram mantidos com iluminação artificial, em razão de observações realizadas à noite.

Para o tempo de ruminação, foram somados os tempos de regurgitação, remastigação e redeglutição do bolo alimentar, e o tempo de apreensão e de ingestão incluiu a apreensão propriamente dita, a manipulação do alimento, a mastigação e a deglutição do bolo alimentar. O ócio representou o tempo de não apreensão e ingestão e o de não ruminação.

Para o ensaio de digestibilidade, foi realizada a coleta total de fezes durante dois dias de cada período experimental. O material coletado, pesado e separado em amostras compostas por animal foi armazenado a $-15^{\circ} \mathrm{C}$. As amostras foram pré-secas em estufa de ventilação forçada, a $65^{\circ} \mathrm{C}$ por 72 horas, processadas em moinho com peneira de $1 \mathrm{~mm}$ e acondicionadas em sacos plásticos para posteriores análises laboratoriais. Também foram calculadas as eficiências de consumo e ruminação em função do consumo de matéria seca (MS) e de fibra em detergente neutro (FDN; g/min).
Para MS, matéria orgânica (MO), PB e extrato etéreo (EE), adotaram-se as técnicas descritas em Silva e Queiroz (2002). A determinação da FDN foi realizada segundo técnica de Van Soest et al. (1991). Carboidratos não fibrosos (CNF) foram obtidos pela equação descrita por Sniffen et al. (1992): $\mathrm{CNF}=100-(\% \mathrm{~PB}+\% \mathrm{EE}+\%$ Cinzas $)$ - FDN. Nutrientes digestíveis totais (NDT) foram calculados por equações com base no NRC (Nutrients..., 2001), em que: Consumo de $\mathrm{NDT}=\mathrm{PBD}+($ EED x 2,25) $+\mathrm{CCHOTD}$, em que D significa digestível (D); e \% de NDT = (consumo de NDT/consumo de MS) x100.

Consumo e digestibilidade dos nutrientes foram avaliados por meio de análise de variância e com 5\% de significância, utilizando-se SAEG (Sistema..., 1997). Os modelos foram escolhidos com base na significância dos coeficientes de regressão utilizando-se o teste $\mathrm{F}$ e adotando-se $10 \%$ de probabilidade.

\section{RESULTADOS E DISCUSSÃO}

Não houve efeito do teor de concentrado sobre as atividades de hidratação, porém as atividades de apreensão e ingestão e de ruminação diminuíram linearmente $(\mathrm{P} \leq 0,05)$ em função do teor de concentrado (Tab. 2). Os animais que receberam $60 \%$ de concentrado na dieta apresentaram menor tempo para essas duas atividades, aumentando, assim, o tempo de ócio.

Tabela 2. Tempo (minutos) despendido nas atividades comportamentais de apreensão e ingestão de alimento, de ingestão de água (hidratação), de ruminação e de ócio em função do teor de concentrado na dieta de vacas leiteiras

\begin{tabular}{|c|c|c|c|c|c|c|c|}
\hline \multirow{2}{*}{ Variável } & \multicolumn{4}{|c|}{ Concentrado (\%) } & \multirow[t]{2}{*}{$\mathrm{P}$} & \multirow{2}{*}{$\begin{array}{c}\text { Equação de } \\
\text { regressão }\end{array}$} & \multirow[t]{2}{*}{$\mathrm{R}^{2}$} \\
\hline & 30 & 40 & 50 & 60 & & & \\
\hline Apreensão & $292,50 \pm$ & $276,25 \pm$ & $217,50 \pm$ & $191,25 \pm$ & 0,03548 & $\hat{\mathrm{Y}}=407,5-3,625 . n$ & 0,96 \\
\hline e ingestão & 12,99 & 22,39 & 40,01 & 28,96 & & & \\
\hline Hidratação & $\begin{array}{c}22,48 \pm \\
4,33\end{array}$ & $\begin{array}{c}33,60 \pm \\
9,43\end{array}$ & $\begin{array}{c}33,42 \pm \\
14,19\end{array}$ & $\begin{array}{c}30,49 \pm \\
6,12\end{array}$ & - & - & - \\
\hline Ruminação & $\begin{array}{c}483,75 \pm \\
45,56\end{array}$ & $\begin{array}{c}408,75 \pm \\
44,31\end{array}$ & $\begin{array}{c}360,00 \pm \\
44,78\end{array}$ & $\begin{array}{c}285,00 \pm \\
61,64\end{array}$ & 0,03401 & $\hat{Y}=674,625-6,450 . n$ & 0,99 \\
\hline Ócio & $\begin{array}{c}570,00 \pm \\
67,77\end{array}$ & $\begin{array}{c}787,50 \pm \\
33,26\end{array}$ & $\begin{array}{c}821,25 \pm \\
32,61\end{array}$ & $\begin{array}{c}933,75 \pm \\
75,34\end{array}$ & 0,05013 & $\hat{\mathrm{Y}}=271,875+11,250 . \mathrm{n}$ & 0,91 \\
\hline
\end{tabular}

$\mathrm{n}=$ teor de concentrado.

Estes resultados assemelham-se aos de Mendes Neto et al. (2007), ao afirmarem que o tempo de ruminação difere para concentrados e alimentos finamente triturados ou peletizados em relação ao mesmo alimento in natura. Em trabalho com novilhas mestiças Holandês-Zebu, Queiroz et al. (2001) observaram que o comportamento alimentar é influenciado pelo teor de FDN da dieta, com maior tempo despendido em ingestão e em ruminação para dietas com alto teor de fibra, semelhante ao presente trabalho.

Na comparação entre os teores de 30 e $60 \%$ de concentrado na dieta, observa-se maior tempo 
gasto para consumo e ruminação entre os animais que receberam dietas com maior proporção de volumoso, sendo que a dieta com $60 \%$ de concentrado proporcionou o menor tempo de apreensão e ingestão e de ruminação, em razão da elevada densidade energética da dieta e menor teor de FDN (Tab. 2).

Segundo Pereira et al. (2007), novilhas de diferentes grupos genéticos, alimentadas com rações com 60\% de FDN, despenderam 28,0; 15,8; e 20,2\% mais tempo com atividades de alimentação, ruminação e mastigação total, respectivamente, que os animais alimentados com dietas que continham 30\% de FDN.

Com o aumento do concentrado, houve aumento linear da quantidade de alimento consumido (g/min), e houve efeito $(\mathrm{P}<0,05)$ sobre a eficiência de consumo e ruminação da MS, com médias de 45,68 e 29,02g/min, respectivamente. A eficiência de ruminação da FDN apresentou média de 19,51g/min na dieta com $60 \%$ do concentrado, apresentando efeito positivo para o tratamento das dietas (Tab. 3).

Tabela 3. Eficiência de consumo e de ruminação (g/min) de matéria seca e de fibra em detergente neutro em função do teor de concentrado na dieta de vacas leiteiras

\begin{tabular}{|c|c|c|c|c|c|c|c|}
\hline \multirow{2}{*}{ Variável } & \multicolumn{4}{|c|}{ Concentrado (\%) } & \multirow[t]{2}{*}{$\mathrm{P}$} & \multirow{2}{*}{ Equação de regressão } & \multirow{2}{*}{$\mathrm{R}^{2}$} \\
\hline & 30 & 40 & 50 & 60 & & & \\
\hline & \multicolumn{4}{|c|}{ Eficiência (g/min) } & & & \\
\hline EC-MS & $34,43 \pm 3,06$ & $44,55 \pm 3,55$ & $46,54 \pm 11,56$ & $57,21 \pm 4,72$ & 0,01089 & $\hat{\mathrm{Y}}=13,3951+0,717509 . \mathrm{n}$ & 0,95 \\
\hline $\begin{array}{l}\text { EC- } \\
\text { FDN }\end{array}$ & $18,41 \pm 1,63$ & $23,06 \pm 1,83$ & $23,28 \pm 5,78$ & $27,61 \pm 2,28$ & 0,02973 & $\hat{Y}=10,2452+0,285459 . n$ & 0,91 \\
\hline ER-MS & $23,98 \pm 3,99$ & $24,26 \pm 3,72$ & $27,41 \pm 3,02$ & $40,42 \pm 6,46$ & 0,00258 & $\hat{\mathrm{Y}}=5,14278+0,530531 . \mathrm{n}$ & 0,76 \\
\hline $\begin{array}{l}\text { ER- } \\
\text { FDN }\end{array}$ & $12,82 \pm 2,13$ & $12,55 \pm 1,92$ & $13,71 \pm 1,51$ & $19,51 \pm 3,12$ & 0,00763 & $\hat{\mathrm{Y}}=4,96849+0,215157 . \mathrm{n}$ & 0,70 \\
\hline
\end{tabular}

EC-MS = eficiência de consumo de matéria seca; EC-FDN= eficiência de consumo da fibra em detergente neutro; ER-MS = eficiência de ruminação da matéria seca; ER-FDN= eficiência de ruminação da fibra em detergente neutro. $\mathrm{n}=$ teor de concentrado.

O comportamento ingestivo de vacas leiteiras estabuladas que receberam silagem de milho ou cana-de-açúcar em duas relações volumoso:concentrado - 50:50 e 60:40 - foi analisado por Mendonça et al. (2004), e não foram observadas diferenças nos tempos despendidos com alimentação (ato de apreender e ingerir) e ruminação, e isto difere dos resultados apresentados neste trabalho, em que o aumento do teor de concentrado da dieta influenciou linearmente a eficiência de consumo e ruminação (g/min).

Houve efeito linear do teor de concentrado sobre o consumo dos nutrientes da dieta, com exceção do consumo de FDN, que se apresentou de forma quadrática e alcançou o máximo de consumo com 58,3\% do concentrado, correspondendo a 10,82kg/dia de MS (Tab. 4), o que pode ser atribuído às características próprias do alimento e composição do concentrado e das dietas.

Ao trabalharem com teores crescentes de ureia na dieta de vacas leiteiras com $60 \%$ de silagem de milho e $40 \%$ de concentrado, Oliveira et al.
(2001) também observaram efeito quadrático no consumo de FDN. Nesse caso, o consumo máximo foi de 6,99kg/dia ou $1,6 \%$ do peso vivo. Geralmente no aumento do teor de concentrado, ocorre substituição de FDN, de carboidrato de digestão média pelos CNF, que têm elevada digestibilidade (Paixão et al., 2007), o que possivelmente esteja relacionado à melhora no consumo dos nutrientes. Tal fato foi observado por Dias et al. (2008), que trabalharam com bagaço de mandioca para novilhas e verificaram que o teor de FDN não influenciou o consumo de MS, pois, com a redução da proporção de volumoso, elevou-se a quantidade de CNF da dieta.

Ao avaliarem o efeito do teor de concentrado em dietas isoproteicas (12\% PB), em ensaio com novilhos, Gesualdi Jr. et al. (2000) encontraram maior consumo para os teores entre 37,5 e 50,0\% de concentrado na dieta, o que difere do presente trabalho, em que se observou aumento linear do consumo em dietas com $13 \%$ de $\mathrm{PB}$. 
Os maiores consumos de MS, PB, EE e NDT foram observados com o teor de $60 \%$ de concentrado, em função da dieta fornecida, que, com o aumento do CNF, melhorou a disponibilidade de PB e EE e maior consumo de EE. No entanto, Ítavo et al. (2002b), ao trabalharem com novilhos, não observaram influência no consumo de NDT em função do teor de concentrado da dieta, sugerindo que as dietas supriram as exigências de mantença dos animais.

O aumento do teor de concentrado na dieta influenciou o consumo de MS, com média de 2,22\% do peso corporal (PC), diferentemente de Modesto et al. (2008), que utilizaram silagem de rama de mandioca em substituição à silagem de milho em dietas de vacas não lactantes, e não observaram alteração no consumo de MS, cuja média foi de 2,03\% do PC.

Não houve efeito do teor de concentrado sobre a digestibilidade dos nutrientes das dietas (Tab. 5).
Observa-se média de 63,8\% para digestibilidade da FDN, superior aos 49,1\% encontrados em trabalho com bezerros da raça Holandesa (Burger et al., 2000). No entanto, Cardoso et al. (2000), ao avaliarem o efeito do teor de concentrado sobre o consumo e a digestibilidade aparente total e parcial, constataram que a maior participação do concentrado na dieta, com aumento linear na digestibilidade dos nutrientes, não influenciou o local de digestão, atribuído à maior concentração de carboidratos totais digestíveis em relação aos carboidratos estruturais.

Ítavo et al. (2002b), ao trabalharem com diferentes teores de concentrado e de PB na dieta de bovinos Nelore, não observaram influência na digestibilidade da FDN, com média de 74,2\%, sugerindo que não houve efeito associativo ou qualquer influência da quantidade de concentrado da dieta sobre a digestão da fibra.

Tabela 4. Média, erro-padrão da média e equações de regressão ajustadas para consumo de nutrientes e consumo de matéria seca e fibra em detergente neutro $\mathrm{kg} /$ dia e porcentagem do peso corporal de vacas leiteiras alimentadas com diferentes teores de concentrado na dieta

\begin{tabular}{|c|c|c|c|c|c|c|c|c|}
\hline \multirow[t]{2}{*}{ Item } & \multicolumn{4}{|c|}{ Concentrado (\%) } & \multirow{2}{*}{$\begin{array}{l}\text { Equação de } \\
\text { regressão }\end{array}$} & \multirow{2}{*}{$\mathrm{R}^{2}$} & \multirow{2}{*}{$\mathrm{P}$} & \multirow{2}{*}{ CV(\%) } \\
\hline & 30 & 40 & 50 & 60 & & & & \\
\hline & \multicolumn{4}{|c|}{$\mathrm{kg} / \mathrm{dia}$} & & & & \\
\hline CMS & $8,63 \pm 0,24$ & $9,44 \pm 0,31$ & $10,44 \pm 0,26$ & $10,95 \pm 0,56$ & $\begin{array}{l}\hat{\mathrm{Y}}=6,31487+ \\
0,0772929 . \mathrm{n}\end{array}$ & 0,96 & 0,0010 & 10,44 \\
\hline CMO & $8,18 \pm 0,23$ & $9,07 \pm 0,24$ & $10,04 \pm 0,20$ & $10,51 \pm 0,42$ & $\begin{array}{l}\hat{Y}=5,86795+ \\
0,0796421 . n\end{array}$ & 0,98 & 0,0012 & 7,69 \\
\hline СРВ & $1,15 \pm 0,04$ & $1,25 \pm 0,04$ & $1,35 \pm 0,03$ & $1,38 \pm 0,08$ & $\begin{array}{l}\hat{\mathrm{Y}}=0,934445+ \\
0,0770073 . \mathrm{n}\end{array}$ & 0,95 & 0,0020 & 7,54 \\
\hline CEE & $0,28 \pm 0,01$ & $0,35 \pm 0,01$ & $0,43 \pm 0,01$ & $0,50 \pm 0,03$ & $\begin{array}{l}\hat{\mathrm{Y}}=0,0457456+ \\
0,00760619 . \mathrm{n}\end{array}$ & 0,99 & 0,0001 & 8,62 \\
\hline CFDN & $4,56 \pm 0,11$ & $4,88 \pm 0,10$ & $5,22 \pm 0,08$ & $5,20 \pm 0,16$ & $\begin{array}{l}\hat{Y}=2,24446+ \\
0,0986692 . n- \\
0,00084559 . n^{2}\end{array}$ & 0,87 & 0,0202 & 10,09 \\
\hline CCNF & $2,19 \pm 0,04$ & $2,59 \pm 0,03$ & $3,04 \pm 0,07$ & $3,44 \pm 0,10$ & $\begin{array}{l}\hat{Y}=0,936675+ \\
0,0417690 . n\end{array}$ & 0,99 & 0,0001 & 13,89 \\
\hline \multirow[t]{2}{*}{ CNDT } & $6,16 \pm 0,17$ & $6,41 \pm 0,09$ & $7,47 \pm 0,16$ & $7,89 \pm 0,35$ & $\begin{array}{l}\hat{\mathrm{Y}}=4,16839+ \\
0,0625139 . \mathrm{n}\end{array}$ & 0,98 & 0,0001 & 15,20 \\
\hline & \multicolumn{4}{|c|}{ \% do peso corporal } & & & & \\
\hline CMS & $1,93 \pm 0,06$ & $2,11 \pm 0,06$ & $2,38 \pm 0,10$ & $2,45 \pm 0,15$ & $\begin{array}{l}\hat{Y}=1,41727+ \\
0,0177785 . n\end{array}$ & 0,96 & 0,0014 & 5,76 \\
\hline CFDN & $1,03 \pm 0,02$ & $1,09 \pm 0,01$ & $1,19 \pm 0,03$ & $1,18 \pm 0,04$ & $\begin{array}{l}\hat{Y}=0,43854+0 \\
0265342 \cdot n- \\
0,00023634 \cdot n^{2}\end{array}$ & 0,87 & 0,0350 & 5,23 \\
\hline
\end{tabular}

$\mathrm{C}$ = consumo. $\mathrm{MS}=$ matéria seca; $\mathrm{MO}=$ matéria orgânica; $\mathrm{PB}=$ proteína bruta; $\mathrm{EE}=$ extrato etéreo; $\mathrm{FDN}=$ fibra em detergente neutro; $\mathrm{CNF}=$ carboidratos não fibrosos; $\mathrm{NDT}=$ nutrientes digestíveis totais; $\mathrm{n}=$ nível de concentrado. 


\section{Goularte et al.}

Tabela 5. Média e erro-padrão da média para digestibilidade aparente total de nutrientes em vacas leiteiras alimentadas com diferentes teores de concentrado na dieta

\begin{tabular}{|c|c|c|c|c|c|c|}
\hline \multirow[t]{2}{*}{ Item } & \multicolumn{4}{|c|}{ Concentrado (\%) } & \multirow{2}{*}{$\mathrm{P}(\leq 0,05)$} & \multirow{2}{*}{$\mathrm{CV}(\%)$} \\
\hline & 30 & 40 & 50 & 60 & & \\
\hline DMS (\%) & $69,61 \pm 2,51$ & $64,58 \pm 1,33$ & $67,97 \pm 2,14$ & $68,31 \pm 3,63$ & 0,3240 & 7,53 \\
\hline DMO (\%) & $71,60 \pm 2,20$ & $66,92 \pm 1,20$ & $70,33 \pm 2,25$ & $71,32 \pm 3,95$ & 0,2967 & 7,28 \\
\hline DPB (\%) & $72,95 \pm 1,54$ & $65,88 \pm 1,51$ & $66,94 \pm 1,88$ & $68,35 \pm 4,65$ & 0,3109 & 7,98 \\
\hline DEE (\%) & $80,32 \pm 2,29$ & $78,13 \pm 0,22$ & $81,56 \pm 3,58$ & $83,66 \pm 1,97$ & 0,2264 & 5,80 \\
\hline DFDN (\%) & $65,01 \pm 2,97$ & $60,14 \pm 1,78$ & $65,35 \pm 2,62$ & $64,73 \pm 4,10$ & 0,2501 & 9,38 \\
\hline DCNF (\%) & $71,93 \pm 2,36$ & $68,15 \pm 2,88$ & $72,16 \pm 2,41$ & $75,68 \pm 3,15$ & 0,2043 & 6,78 \\
\hline NDT (\%) & $83,53 \pm 2,53$ & $78,38 \pm 1,05$ & $78,74 \pm 3,46$ & $80,52 \pm 6,16$ & 0,2147 & 9,54 \\
\hline
\end{tabular}

$\mathrm{D}=$ digestibilidade; $\mathrm{MS}$ = matéria seca; $\mathrm{MO}=$ matéria orgânica; $\mathrm{PB}=$ proteína bruta; $\mathrm{EE}=$ extrato etéreo; FDN= fibra em detergente neutro; $\mathrm{CNF}=$ carboidratos não fibrosos; NDT= nutrientes digestíveis totais.

As digestibilidades da PB e do EE não sofreram influência do teor de concentrado da dieta, resultado semelhante ao apresentado por Ítavo et al. (2002c), que também não observaram influência do teor de concentrado sobre a digestibilidades da PB e do EE, com médias de 78,2 e $83,5 \%$, respectivamente, considerando-se dietas de alta digestibilidade.

No presente experimento, o aumento do concentrado aumentou o consumo de MS, o que não influenciou a digestibilidade dos nutrientes. As médias dos valores de digestibilidade do EE e dos NDT foram de 80,9 e $72,0 \%$, respectivamente, indicando dietas de elevado valor nutricional. Oliveira et al. (2001) também não verificaram efeito sobre a digestibilidade aparente do EE, em função de diferentes teores de EE na dieta de vacas leiteiras.

\section{CONCLUSÕES}

O tempo despendido em alimentação e ruminação diminuiu, e o tempo de ócio aumentou, linearmente, com o aumento da proporção de concentrado na dieta. O aumento de 30 para $60 \%$ de concentrado na dieta influenciou quadraticamente o consumo de FDN e resultou em aumento no consumo de nutrientes. O aumento do concentrado aumentou o consumo de MS, mas não alterou a digestibilidade dos nutrientes da dieta, e influenciou linearmente a eficiência de ruminação e o consumo de MS e FDN, com redução do tempo gasto com ruminação.

\section{REFERÊNCIAS BIBLIOGRÁFICAS}

ALBRIGHT, J.L. Nutrition, feeding and calves: feeding behaviour of dairy cattle. J. Dairy Sci., v.76, p.485-498, 1993.

ALTMAN, J. Observational study of behavior: sampling methods. Behaviour, v.49, p.227-267, 1974.

ALVIM, M.J.; VERNEQUE, R.S.; VILELA, D. et al. Estratégia de fornecimento de concentrado para vacas da raça Holandesa em pastagem de coastcross. Pesq. Agrop. Bras., v.34, p.1711-1720, 1999.

BEAUCHEMIN, K.A. Effects of digestive and ruminative mastication on digestion of forage by cattle. Anim. Feed Sci. Techn., v.40, p.41-56, 1992.

BURGER, P.J.; PEREIRA, J.C.; SILVA, J.F.C. et al. Consumo e digestibilidade aparente total e parcial em bezerros Holandeses alimentados com dietas contendo diferentes níveis de concentrado. Rev. Bras. Zootec., v.29, p.206-214, 2000.

CABRAL, L.S.; VALADARES FILHO, S.C.; DETMANN, E. et al. Avaliação de indicadores na estimação da excreção fecal e da digestibilidade em ruminantes. Rev. Bras. Saúde Prod. Anim., v.9, p.29-34, 2008.

CARDOSO, R.C.; VALADARES FILHO, S.C.; COELHO DA SILVA, J.F. et al. Consumo e digestibilidades aparentes totais e parciais de rações contendo diferentes níveis de concentrado, em novilhos F1 Limousin x Nelore. Rev. Bras. Zootec., v.29, p.1844-1852, 2000.

DAMASCENO, J.C.; BACCARI JÚNIOR, F.; TARGA, L.A. Respostas comportamentais de vacas Holandesas, com acesso à sombra constante ou limitada. Pesq. Agrop. Bras., v.34, p.709-715, 1999. 
DESWYSEN, A.G.; DUTILLEUL, P.; GODFRIN, J.P. et al. Nycterohemeral eating and ruminating pattern in heifers fed grass or corn silage: analysis by finite flourier transform. $J$. Anim. Sci., v.71, p.2739-2747, 1993.

DIAS, A.M.; SILVA, F.F.; VELOSO, C.M. et al. Bagaço de mandioca em dietas de novilhas leiteiras: consumo de nutrientes e desempenho produtivo. Arq. Bras. Med. Vet. Zootec., v.60, p.987-995, 2008.

FREITAS, D.; BERCHIELLI, T.T.; SILVEIRA, R.N. et al. Consumo e digestibilidade aparente total e parcial de rações com cana-de-açúcar, casca e raspa de mandioca ensiladas com polpa cítrica. Rev. Bras. Zootec., v.31, supl., p.15311542, 2002.

GESUALDI Jr., A.; PAULINO, M.F.; VALADARES FILHO, S.C. et al. Níveis de concentrado na dieta de novilhos F1 Limousin $\mathrm{x}$ Nelore: consumo, conversão alimentar e ganho de peso. Rev. Bras. Zootec., v.29, p.1458-1466, 2000.

ÍTAVO, L.C.V.; VALADARES FILHO, S.C.; SILVA, F.F. et al. Comparação de indicadores e metodologia de coleta para estimativas de produção fecal e fluxo de digesta em bovinos. Rev. Bras. Zootec., v.31, p.1833-1839, 2002a.

ÍTAVO, L.C.V.; VALADARES FILHO, S.C.; SILVA, F.F. et al. Níveis de concentrado e proteína bruta na dieta de bovinos Nelore nas fases de recria e terminação: consumo e digestibilidade. Rev. Bras. Zootec., v.31, supl., p.1033-1041, 2002b.

ÍTAVO, L.C.V.; VALADARES FILHO, S.C.; SILVA, F.F. et al. Consumo e digestibilidades aparentes totais e parciais de nutrientes em novilhos alimentados com dietas contendo vários níveis de concentrado. Rev. Bras. Zootec., v.31, supl., p.1543-1552, 2002c.

LEÃO, M.I.; VALADARES FILHO, S.C.; RENNÓ, L.N. et al. Consumos e digestibilidades totais e parciais de carboidratos totais, fibra em detergente neutro e carboidratos não fibrosos em novilhos submetidos a três níveis de ingestão e duas metodologias de coleta de digestas abomasal e omasal. Rev. Bras. Zootec., v.34, p.670-678, 2005.
MENDES NETO, J.; CAMPOS, J.M.S.; VALADARES FILHO, S.C. et al. Comportamento ingestivo de novilhas leiteiras alimentadas com polpa cítrica em substituição ao feno de capim-tifton 85. Rev. Bras. Zootec., v.36, p.618-625, 2007.

MENDONÇA, S.S.; CAMPOS, J.M.S.; VALADARES FILHO, S.C. et al. Comportamento ingestivo de vacas leiteiras alimentadas com dietas à base de cana-de-açúcar ou silagem de milho. Rev. Bras. Zootec., v.33, p.723-728, 2004.

MODESTO, E.C.; SANTOS, G.T.; ZAMBOM, M.A. et al. Consumo, digestibilidade e parâmetros ruminais em vacas gestantes alimentadas com silagem de rama de mandioca. Rev. Bras. Zootec., v.37, p.944-950, 2008.

NUTRIENT requirements of dairy cattle. 7.ed. Washington, DC: National Academy, 2001. 381p.

OLIVEIRA, A.S.; VALADARES, R.F.D.; VALADARES FILHO, S.C. et al. Consumo, digestibilidade aparente, produção e composição do leite em vacas alimentadas com quatro níveis de compostos nitrogenados não proteicos. Rev. Bras. Zootec., v.30, p.1358-1366, 2001.

PAIXÃO, M.L.; VALADARES FILHO, S.C.; LEÃO, M.I. et al. Variação diária na excreção de indicadores interno (FDAi) e externo $\left(\mathrm{Cr}_{2} \mathrm{O}_{3}\right)$, digestibilidade e parâmetros ruminais em bovinos alimentados com dietas contendo ureia ou farelo de soja. Rev. Bras. Zootec., v.36, p.739747, 2007.

PALMQUIST, D.L. Use of fats in diets for lactating dairy cows. In: Fats in animal nutrition. Boston: Butterworth, 1984. p.357-360.

PARANHOS DA COSTA, M.J.R.; COSTA E SILVA, E.V.; CHIQUITELLI NETO, M. et al. Contribuição dos estudos de comportamento de bovinos para implementação de programas de qualidade de carne. In: ENCONTRO ANUAL DE ETOLOGIA, 20., 2002, Natal. Anais... Natal: Sociedade Brasileira de Etologia, 2002. p.71-89.

PATERSON, J.A.; BELYEA, R.L.; BOWMAN, J.P. et al. The impact of forage quality and supplementation regime on ruminant animal intake and performance. In: FAHEY Jr., G.C. (Ed). Forage quality, evaluation and utilization. Madison: American Society of Agronomy. 1994. p.59-114. 


\section{Goularte et al.}

PEREIRA, J.C.; CUNHA, D.N.F.V.; CECON, P.R. et al. Comportamento ingestivo e taxa de passagem de partículas em novilhas leiteiras de diferentes grupos genéticos submetidas a dietas com diferentes níveis de fibra. Rev. Bras. Zootec., v.36, supl., p.2134-2142, 2007.

QUEIROZ, A.C.; NEVES, J.S.; MIRANDA, L.F. et al. Efeito do nível de fibra e da fonte de proteína sobre o comportamento alimentar de novilhas mestiças Holandês-Zebu. Arq. Bras. Med. Vet. Zootec., v.53, p.84-88, 2001.

RESENDE, F.D.; QUEIROZ, A.C.; OLIVEIRA, J.V. Bovinos mestiços alimentados com diferentes proporções de volumoso:concentrado. 1. Digestibilidade aparente dos nutrientes, ganho de peso e conversão alimentar. Rev. Bras. Zootec., v.30, p.261-269, 2001.

SILVA, D.J.; QUEIROZ, A.C. Análise de alimentos: métodos químicos e biológicos. 3.ed. Viçosa: UFV, 2002. 235p.
SNIFFEN, C.J.; O'CONNOR, J.D., VAN SOEST, P.T. et al. A net carbohydrate and protein system for evaluating cattle diets. II. Carbohydrate and protein availability. J. Anim. Sci., v.70, p.3562-3577, 1992.

SNIFFEN, C.J.; BEVERLY, R.W.; MOONEY, C.S. et al. Nutrient requirement versus supply in dairy cow: Strategies to account for variability. $J$. Dairy Sci., v.76, p.3160-3178, 1993.

SOUZA, S.R.M.B.O.; ÍTAVO, L.C.V.; RIMOLI, J. et al. Comportamento ingestivo diurno de bovinos em confinamento e em pastagens. Arch. Zootec., v.56, p.67-70, 2007.

VAN SOEST, P.J. Nutritional ecology of the ruminant. 2.ed. Ithaca: Constock Publishing Associates, 1994. 476p.

VAN SOEST, P.J.; ROBERTSON, J.B.; LEWIS, B.A. Methods for dietary fiber, neutral detergent fiber, and no starch polysaccharides in relation to animal nutrition. J. Dairy Sci., v.74, p.35833597, 1991. 